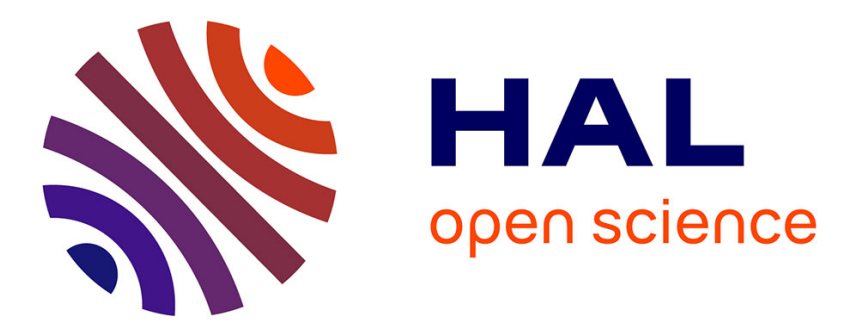

\title{
Selection for productivity and robustness traits in pigs
}

S. Hermesch, L. Li, A. B. Doeschl-Wilson, Hélène Gilbert

\section{To cite this version:}

S. Hermesch, L. Li, A. B. Doeschl-Wilson, Hélène Gilbert. Selection for productivity and robustness traits in pigs. Animal Production Science, 2015, 55 (11), pp.1437-1447. 10.1071/AN15275 . hal02634861

\section{HAL Id: hal-02634861 \\ https://hal.inrae.fr/hal-02634861}

Submitted on 27 May 2020

HAL is a multi-disciplinary open access archive for the deposit and dissemination of scientific research documents, whether they are published or not. The documents may come from teaching and research institutions in France or abroad, or from public or private research centers.
L'archive ouverte pluridisciplinaire HAL, est destinée au dépôt et à la diffusion de documents scientifiques de niveau recherche, publiés ou non, émanant des établissements d'enseignement et de recherche français ou étrangers, des laboratoires publics ou privés. 


\title{
Selection for productivity and robustness traits in pigs
}

\author{
S. Hermesch ${ }^{\mathrm{A}} \mathrm{D}$, L. Li $^{\mathrm{A}}$, A. B. Doeschl-Wilson ${ }^{\mathrm{B}}$ and H. Gilbert ${ }^{\mathrm{C}}$

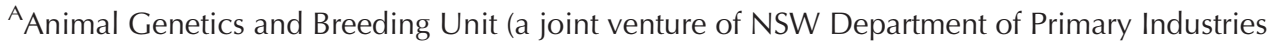 \\ and University of New England), UNE, Armidale, NSW 2351, Australia. \\ BThe Roslin Institute, University of Edinburgh, Easter Bush EH25 9RG, UK. \\ CINRA, UMR1388 GenPhySE, F-31326 Castanet-Tolosan, France. \\ DCorresponding author. Email: Susanne.Hermesch@une.edu.au
}

\begin{abstract}
Pig breeding programs worldwide continue to focus on both productivity and robustness. This selection emphasis has to be accompanied by provision of better-quality environments to pigs to improve performance and to enhance health and welfare of pigs. Definition of broader breeding objectives that include robustness traits in addition to production traits is the first step in the development of selection strategies for productivity and robustness. An approach has been presented which facilitates extension of breeding objectives. Post-weaning survival, maternal genetic effects for growth as an indicator of health status and sow mature weight are examples of robustness traits. Further, breeding objectives should be defined for commercial environments and selection indexes should account for genotype by environment interactions $(\mathrm{GxE})$. Average performances of groups of pigs have been used to quantify the additive effects of multiple environmental factors on performance of pigs. For growth, GxE existed when environments differed by $60 \mathrm{~g} /$ day between groups of pigs. This environmental variation was observed even on well managed farms. Selection for improved health of pigs should focus on disease resistance to indirectly reduce pathogen loads on farms and on disease resilience to improve the ability of pigs to cope with infection challenges. Traits defining disease resilience may be based on performance and immune measures, disease incidence or survival rates of pigs. Residual feed intake is a trait that quantifies feed efficiency. The responses of divergent selection lines for residual feed intake to various environmental challenges were often similar or even favourable for the more efficient, low residual feed intake line. These somewhat unexpected results highlight the need to gain a better understanding of the metabolic differences between more or less productive pigs. These physiological differences lead to interactions between the genetic potential of pigs for productivity and robustness and the prevalence of specific environmental conditions.
\end{abstract}

Additional keywords: breeding objective, disease resilience, environmental variation, genotype by environment interactions, residual feed intake.

Received 4 June 2015, accepted 31 August 2015, published online 12 October 2015

\section{Introduction}

Selection for efficiency and productivity has been the longterm focus of pig breeding programs worldwide leading to considerable genetic gains in production levels of pigs. These genetic improvements in efficiency and productivity, however, have high physiological demands, which may have unfavourable consequences for the robustness of animals (e.g. Knap and Rauw 2009; Prunier et al. 2010). Robustness has recently been described as a central concept in reconciling productivity and feed efficiency with health, adaptation, welfare and reproduction (Phocas et al.2014). This general description of robustness provides an overview of the concept of robustness and requires development of specific applications in animal breeding. In pig breeding, robust pigs were defined by Knap (2005) 'as pigs that combine high production potential with resilience to external stressors, allowing for unproblematic expression of high production potential in a wide variety of environmental conditions'. Knap (2005) provided examples of robustness traits including pre-weaning survival of piglets and rebreeding success of sows. For growing pigs, additional robustness traits may be extended to include survival of growing pigs, disease incidence and possibly maternal genetic components that improve growth and health status of growing pigs. Further, the concept of environmental sensitivity mentioned by Knap (2005) in the definition of robustness can be applied to a wide range of environmental descriptors including the incidence of disease and pathogen load to better describe specific infection challenges for the definition of disease resilience.

A wide range of research continues to focus on aspects of robustness worldwide. In Australia, the development of healthy, robust pig genotypes is the aim of one research program of the Cooperative Research Centre for High Integrity Australian Pork. This review will provide an overview of selection for both productivity and robustness in pigs. This is a very extensive research topic and not all aspects can be covered. In particular, genomic selection is often mentioned as a selection strategy for health and robustness traits because these traits are difficult to 
measure and are often not available for selection candidates before selection. However, genomic selection still requires accurate definition of phenotypes, which has been the focus of this overview of research currently underway in Australia.

\section{Rate of genetic improvement}

Selective breeding leads to genetic improvement of animals and is based on quantitative genetics, which was described by Nicholas (1997) as 'sufficiently mathematical to strike fear into the hearts of many practical pig breeders'. However, Nicholas (1997) also pointed out that 'pig breeders around the world have been at the forefront of the practical application of quantitative genetics in pig improvement programs.' This statement is also true for Australian pig breeders who adopted genetic technologies based on Best Linear Unbiased Predictions in the early 1990s to identify genetically superior animals more accurately. The initial selection emphasis was on growth, backfat and feed conversion ratio (FCR) whereas litter size was considered in selection decisions slightly later when breeders were more familiar with Best Linear Unbiased Prediction-based selection procedures. In regard to selection for FCR, it is ideal if information about feed intake of individual pigs is available from environments that represent on-farm conditions. Recording of feed intake in grouphoused pigs required development of electronic feeders (Eissen et al. 1998; McSweeny et al. 2001; Casey et al. 2005), which are not used by all breeders. The development of juvenile insulin like growth factor 1 (IGF-1) as a selection criterion for efficiency and leanness in the late 1990s, as summarised by Bunter et al. (2005), aided genetic improvement of FCR. Selection for litter size has unfavourable consequences for piglet survival and Australian pig breeders adopted various strategies for genetic improvement of piglet survival (Hermesch 2001; Bunter 2009). The list of traits considered in selection decisions continues to grow, which demonstrates the ability and willingness of pig breeders to adopt research findings about new traits with economic and societal importance.

The rate of genetic improvement is quantified by the genetic trend, which is calculated as the mean of estimated breeding values (EBV) of animals born each year. The genetic trends of five traits from 2000 to 2005 were summarised by Hermesch (2006) using data from 28 Australian pig populations. The average annual genetic gain was $5.02 \mathrm{~g}$ /day for growth rate,
$-0.15 \mathrm{~mm}$ for backfat, $-0.01 \mathrm{~kg}: \mathrm{kg}$ for FCR, $0.05 \mathrm{~mm}$ for muscle depth and 0.07 piglets for litter size during this time period (Table 1). These genetic trends were then compared with phenotypic trends, which describe the change in observed performance over time due to changes in genetic and nongenetic factors. Phenotypic trends were summarised for a subset of these populations representing eight herds. Average annual phenotypic improvements were similar in magnitude to genetic trends with annual improvements in performance of $3.80 \mathrm{~g}$ /day for growth rate, $-0.10 \mathrm{~mm}$ for backfat and 0.09 for litter size. There was, however, substantial variation in phenotypic trends between herds and phenotypic performances differed substantially between years within herds. Therefore, changes in environmental conditions may fully override genetic gains. This highlights the need to monitor environmental conditions on farm more accurately in order to provide improved and more consistent environments to pigs. Optimising environmental conditions on farms is of paramount importance because it not only improves performance, it also enhances health and welfare of pigs.

Genetic gains of traits are usually expressed in the unit of each trait. Therefore, a comparison of genetic gains across traits is not directly possible, even for what might seem to be the same trait. For example, a comparison of genetic gains of growth rate between studies based on the actual unit of the trait (i.e. g/day) may not always be meaningful because growth traits may differ between studies in regard to recording procedures and the models used in genetic analyses. These differences in trait definitions may lead to differences in additive genetic variances, which determine the rate of genetic gain possible for traits. This limitation is overcome if genetic gains are expressed relative to the genetic standard deviation (s.d.) of each trait, making a comparison of genetic gains across traits, studies and even species possible.

The mean annual genetic gains summarised by Hermesch (2006) represented $3-15 \%$ of the genetic s.d. for each trait, whereas genetic gains achieved in the top $25 \%$ populations varied from $13 \%$ to $22 \%$ of the genetic s.d. of each trait. These rates of genetic gain were similar to genetic gains reported for other pig populations (e.g. Knap and Wang 2012) or for the Angus beef population in Australia (Barwick and Henzell 2005). Australian Angus breeders included a substantially higher number of traits in their breeding programs and were still able to achieve genetic gains of $2-19 \%$ of the genetic s.d. for individual traits. Further, rate of genetic gain in profitability had increased

Table 1. Mean annual genetic trends of 28 pig populations in Australia along with annual genetic gains of the top $25 \%$ populations achieved from 2000 until 2005 (Hermesch 2006)

\begin{tabular}{lccc}
\hline Trait & Mean & $\begin{array}{c}\text { Mean of top 25\% ranked } \\
\text { on breeding objective }\end{array}$ & $\begin{array}{c}\text { Mean of top 25\% ranked } \\
\text { on each trait separately }\end{array}$ \\
\hline Growth rate (g/day) & 5.02 & 7.520 & 9.590 \\
Backfat (mm) & -0.15 & -0.260 & -0.280 \\
Feed conversion ratio (kg: $\mathrm{kg})$ & -0.01 & -0.027 & -0.028 \\
Live muscle depth (mm) & 0.05 & 0.014 & 0.200 \\
Number born alive (piglets) & 0.07 & 0.120 & 0.180 \\
Breeding objective $^{\mathrm{A}}$ (\$pig) & 1.06 & 1.920 & - \\
\hline
\end{tabular}

\footnotetext{
${ }^{\mathrm{A}}$ Breeding objective was defined as: $0.049 * \mathrm{EBV}_{\mathrm{ADG}}-2.05 * \mathrm{EBV}_{\mathrm{BF}}-21.1 * \mathrm{EBV}_{\mathrm{FCR}}+1.0 * \mathrm{EBV}_{\mathrm{LMD}}+3.56 * \mathrm{EBV}_{\mathrm{NBA}}$ (Cameron and Crump 2001), where EBV is estimated breeding value, $\mathrm{ADG}$ is growth rate, $\mathrm{BF}$ is backfat, $\mathrm{FCR}$ is feed conversion ratio, LMD is live muscle depth and NBA is number of piglets born alive and \$ represents Australian dollar.
} 
from 1985 until 2005 by extending the number of traits over time while maintaining genetic gains in existing traits. The breeding objective used in this beef example included carcass, meat quality and cow reproductive traits. This shows that it is possible to achieve genetic gains simultaneously in multiple traits and inclusion of additional robustness traits in pig breeding programs is expected to increase gains in breeding objectives.

\section{Definition of breeding objectives}

Breeding objectives combine all economically important traits in a single economic index, which is the basis for selection decisions of animals. Various authors have proposed to include traits describing vitality, uniformity, welfare, and health of animals in pig breeding objectives (Kanis et al. 2005; Knap 2005; Merks et al. 2012). These traits are important to society and describe aspects of robustness. The range of traits affecting profitability of pork production is increasing and seedstock suppliers require greater flexibility in the establishment of company-specific breeding objectives (Barwick et al. 2011). The approach of Amer et al. (2014) and Hermesch et al. (2014a) to derive economic values of traits from an independent sub-model for each trait provides flexibility to pig breeders in setting up breeding objectives. Economic values quantify the change in profit when a trait is changed by one unit, and they are the basis for the economic weights used to combine all economically important traits in breeding objectives.

Economic values are shown for performance and robustness traits of growing pigs in Table 2. Relative to the genetic s.d. of each trait, the magnitude of economic values varied from $\$ 0.47$ to $\$ 6.95$ (Australian dollar) per pig between traits. Well-managed breeding programs can achieve genetic gains of $10-20 \%$ of the genetic s.d. of each trait on average as outlined above. This implies that the proposed breeding objective, which considers both productivity and robustness traits of growing pigs, has the potential to achieve annual rates of genetic gains of about $\$ 2$ to \$4 per pig.

Post-weaning survival, a robustness trait, was the most important breeding objective trait for growing pigs given the assumptions about additive genetic s.d. No information was found in the literature for the genetic s.d. of post-weaning survival, which was derived assuming a survival rate of pigs of $97 \%$ after weaning and a heritability of 0.05 . Post-weaning survival was estimated to be lowly heritable and genetically correlated with pre-weaning survival (Kim Bunter, pers. comm.). In contrast, Dufrasne et al. (2014) found no genetic association between post- and pre-weaning survival. Obviously it is important to obtain accurate genetic parameters for postweaning survival of pigs in order to consider this trait in pig breeding programs more effectively.

Maternal genetic effects represent the genes of the dam affecting the performance of the progeny. Although maternal genetic effects only influence performance of growing pigs indirectly, they may offer opportunities for genetic improvement that so far have been overlooked because the low estimate of maternal genetic effects were regarded as unimportant (Solanes et al. 2004b). However, the genes of the dam affect all progeny in the litter and the economic value for maternal genetic effects of a trait is obtained by multiplying the economic value of the direct genetic effects of the trait of interest with the number of pigs per litter surviving until slaughter (Amer et al. 2014). Maternal genetic effects are expressed per farrowing and represent a trait of the sow that is relevant for maternal lines. Estimates of maternal genetic effects are higher at birth with values of about 0.20 for piglet weight (Hermesch et al. 2001; Solanes et al. 2004a) and decrease continuously for weights of pigs after weaning as the pig matures. Estimates of maternal genetic effects varied from 0.00 to 0.09 for growth and from 0.00 to 0.07 for backfat recorded shortly before slaughter between breeds in different studies (Johnson et al. 2002; Solanes et al. 2004b; Akanno et al. 2013; Hermesch et al. 2014b). These estimates indicate that maternal genetic effects offer opportunities to increase genetic gains in multiple performance traits that describe productivity of pigs. Further, it should be explored whether maternal genetic effects are becoming more important as litter size continues to increase.

Maternal genetic effects may also enhance genetic improvement of robustness traits because the dam is known to provide immunological support to piglets. Maternal genetic effects for immune parameters may be difficult to obtain because estimation of maternal genetic effects requires records from multiple generations. However, growth has been used as a

Table 2. Economic values ${ }^{\mathrm{A}}$ of breeding objective (BO) traits of growing pigs

GSD, genetic standard deviation

\begin{tabular}{llrrr}
\hline Trait & Unit & GSD & \$ $/$ trait unit & $\$ /$ GSD \\
\hline Feed conversion ratio (FCR) & kg feed/kg weight gain & 0.150 & -27.44 & -4.11 \\
Daily feed intake (DFI) & kg feed/day & 0.094 & -36.12 & -3.39 \\
Growth rate (with FCR in BO) & g/day & 30.000 & 0.09 & 2.70 \\
Growth rate (with DFI in BO) & g/day & 30.000 & 0.16 & 4.80 \\
Post-weaning survival (cost-saving approach) & pig survival/pig weaned & 0.038 & 169.74 & 6.45 \\
Post-weaning survival (lost-revenue approach) & pig survival /pig weaned & 0.038 & 182.88 & 6.95 \\
Carcass fat depth & mm & 1.000 & -1.70 & -1.70 \\
Loin weight & $\mathrm{kg}$ & 0.680 & 3.60 & 2.45 \\
Belly weight & $\mathrm{kg}$ & 0.390 & 1.20 & 0.47 \\
Growth rate maternal & $\mathrm{g} /$ day per farrowing & 20.000 & 0.83 & 3.83
\end{tabular}

\footnotetext{
${ }^{\mathrm{A}}$ Based on Hermesch and Jones (2010), Amer et al. (2014) and Hermesch et al. (2014a).

${ }^{\mathrm{B}}$ Australian dollar.

${ }^{\mathrm{C}}$ Growth rate maternal is only part of a breeding objective for maternal lines. The \$/GSD was multiplied by two to account for the fact that sows contribute only half of the genetic component to efficient lean meat growth of commercial pigs.
} 
proxy of health status of pigs and moderate maternal genetic effects for weight traits recorded around weaning may be used to select pigs that are better able to cope with the weaning process.

Finally, maternal genetic effects can be estimated from existing data and do not require any additional information to be recorded. Given the assumed genetic s.d. for growth traits outlined in Table 2, maternal genetic effects were of similar importance to direct genetic effects for growth in maternal breeding objectives. Therefore, maternal genetic effects offer opportunities to increase genetic gain in the breeding objective without the need for any additional investments in recording data.

\section{Robustness traits of sows}

Economic weights for robustness traits of sows include sow longevity, farrowing and pre-weaning survival of piglets (Knap 2005; Amer et al. 2014). Further, sow mature weight may be regarded as a robustness trait of sows when environmental conditions are disadvantageous for larger sows with higher nutritional and housing requirements. The economic weight for sow mature weight includes four economic value components which quantify the effects of (a) energy requirements of gilts, (b) sow maintenance cost, (c) sow capital costs and (d) sow mature weight cull value on profit (Amer et al. 2014). Sow mature weight was the second most important maternal trait after litter size. Selection for growth in pigs results in heavier gilts with heavier piglets and higher lactation feed intake capacity (Bunter et al. 2010). Further, regression of sow weights observed across parities on farm on estimated breeding values for growth of pigs indicated that a genetic gain of $100 \mathrm{~g}$ /day was associated with an increase in sow weight of $30 \mathrm{~kg}$ (Hermesch et al. 2010). However, the pattern of residual and phenotypic correlations estimated by Bunter et al. (2010) also indicated environmental limitations to performance of gilts with high genetic potential for growth. Overall, these findings highlight the need to modify environmental conditions continuously to accommodate the rapidly changing requirements of sows due to selection for lean meat growth and the need to consider sow mature weight in selection decisions.

\section{Variation in environmental conditions}

The environment experienced by pigs is defined through multiple characteristics including temperature, floor space, air quality, nutrition, feeding or vaccination and general health status of pigs. Each one of these environmental characteristics may lead to an environmental stressor when conditions are suboptimal. Hyun et al. (1998) showed that multiple environmental stressors affect growth rate of pigs in an additive manner. It is therefore generally beneficial to remove a single known environmental stressor even when other potentially unknown environmental constraints may still be present.

Specific information about infection challenge on farm is required for the development of selection strategies to improve disease resilience of pigs (Doeschl-Wilson and Lough 2014; Hermesch 2014). The infection challenge experienced by a group of pigs may be based on the average of various immune parameters or pathogen levels of the pigs in a group. Alternatively, infection challenge may be derived from measuring pooled samples of faeces or saliva collected from a group of pigs. Examples of onfarm measurements of pathogen load and their associations with performance and disease were described in the review by Collins (2014). Infection challenge experienced by pigs on farms is not only affected by the amount of potentially interacting pathogens and their virulence, but also by environmental factors such as air quality, temperature and humidity. Collins (2014) suggested that monitoring air quality may provide a better indicator of pig health and growth than monitoring individual pathogen loads because air quality affects growth and health of pigs. Various devices and measurement techniques are now readily available to monitor environmental conditions on farms regularly. These devices and techniques should be implemented by pig producers to provide the best possible environment for pigs raised indoors. Further, these devices offer opportunities for pig breeders to monitor environmental conditions on farm more precisely for the evaluation of genotype by environment interactions (GxE).

\section{Use of performance records}

Information about specific environmental factors such as air quality or specific information about pathogen load, however, is often not available for all groups of pigs. Instead, the average performance of a group of pigs housed together may be used as an environmental descriptor. Groups of pigs may represent farms, sheds, or pigs housed in the same building at the same time period. The time period may consist of weekly batches or may include groups of pigs that started (or finished) the test in the same month. Information available for any trait recorded on farms can be used to obtain an environmental descriptor for genetic analyses or for evaluation of management procedures. Such information has also been used to identify periods of disease prevalent on farms. For example, reproductive records have been used to identify outbreaks of Porcine Reproductive and Respiratory Syndrome (PRRS) on farms (Lewis et al. 2009; Rashidi et al. 2014).

Studies conducted in Australia and France found considerable environmental variation for growth and backfat in herds with good management and health status (Table 3 ). This demonstrates that it is not possible to fully control environmental variation.

Table 3. Number of herds (N-H) and groups (N-G), standard deviations (s.d.) and maximum difference between monthly estimates of the environmental variable (Range) based on growth (E-ADG) or backfat (E-BF)

\begin{tabular}{|c|c|c|c|c|c|c|c|}
\hline \multirow[t]{2}{*}{ Study } & \multirow[b]{2}{*}{$\mathrm{N}-\mathrm{H}$} & \multicolumn{3}{|c|}{ E-ADG (g/day) } & \multicolumn{3}{|c|}{ E-BF (mm) } \\
\hline & & $\mathrm{N}-\mathrm{G}$ & s.d. & Range & $\mathrm{N}-\mathrm{G}$ & s.d. & Range \\
\hline Gilbert et al. (2014) & 1 & 80 & 25.0 & 110 & 44 & 2.0 & 6.9 \\
\hline Hermesch et al. (2015) & 1 & 72 & 13.9 & 67 & 72 & 1.8 & 6.1 \\
\hline $\mathrm{Li}$ and Hermesch (2015) & 9 & 950 & 31.0 & 150 & 950 & 1.0 & 5.0 \\
\hline
\end{tabular}


The exact causes of this environmental variation are not known, however, heat stress is an important environmental factor, especially in Australia. Further, the range of average performances of monthly groups of pigs was $0.41 \mathrm{~kg} /$ day for daily feed intake and $0.32 \mathrm{~kg}: \mathrm{kg}$ for FCR (Hermesch et al. 2015). Differences in average performances of groups were multiplied by the economic value of each trait leading to a maximum economic difference between monthly groups of pigs of $\$ 17.41$ per pig based on an economic index that considered daily feed intake and $\$ 11.78$ per pig for the index that included FCR (Hermesch et al. 2015). These economic differences between groups are expressed per pig and need to be multiplied with the number of pigs per group to obtain total economic differences between groups. It follows that considerable investments to improve environments on farms with good health and management status may still be profitable and should be considered to further improve environmental conditions for pigs on farm.

Performance and health status of pigs are affected by multiple environmental factors. Guy et al. (2012) discussed the mechanisms of resistance and tolerance of pigs to disease and environmental challenges. The use of data routinely collected on farms was emphasised to model and predict selection for disease resistance and disease tolerance. Further, Guy et al. (2012) concluded 'that a simple one-dimensional reaction norm, with pathogen burden as the only explanatory variable, cannot be used. A number of factors need to be taken into account simultaneously, including not only genotype and disease variables, but also descriptors of the environment, as well as any potential interactions'. This aspect may be addressed by using principal component analyses, which have been applied to combine individual environmental variables (e.g. Haskell et al. 2007). Further, Huquet et al. (2012) proposed a definition of the environment based on the local production environment of monthly test days using multiple factor analyses to form environmental clusters. This approach offers the possibility to investigate GxE either via multi-trait analyses, based on a distinct cluster of environments, versus more complex reaction norm models, which require continuous environmental parameters available from the first axis of the factor analysis.

\section{Genotype by environment interactions}

Differences between genotypes in their responses to environmental variation represent GxE, which may be evaluated with multi-trait analyses by defining a trait like growth rate as a different trait in each distinct environment. In pig breeding, GxE have been identified for (a) test stations, nucleus farms and commercial farms; (b) purebred and crossbred pigs; and (c) ad libitum and restricted feeding regimes (e.g. Merks 1989; Lutaaya et al. 2001; Hermesch 2004). Environments, however, may be defined more accurately with specific measurements that describe environmental conditions on a continuous scale. In these cases, reaction norm models, which fit a separate regression coefficient for each genotype on an environmental trajectory, may be used to model GxE (Falconer and Mackay 1996). In pig breeding, reaction norm models have been used to quantify the response of genotypes to varying environmental conditions using information from multiple herds for litter size (Knap and Su 2008; Herrero-Medrano et al. 2015) or growth and backfat (Li and Hermesch 2012). Each study found genetic differences in the responses of sows or progeny of sires to variation in environmental conditions.

Aspects of these two approaches to quantify GxE were combined by $\mathrm{Li}$ and Hermesch (2013), who divided the environmental trajectory based on least squares means for growth rate into seven environmental classes leading to seven growth rate traits along the environmental trajectory. Therefore, the continuous environmental scale was divided into separate environmental classes to define individual growth traits. Differences were found in variance components and heritabilities for growth rate across the environmental trajectory. Further, genetic correlations between these seven growth traits varied from $0.61 \pm 0.16$ to $0.99 \pm 0.02$ and decreased as the difference between environments increased (Fig. 1). A genetic correlation of below 0.80 is generally regarded as biologically significant and traits should be treated as two separate traits in genetic evaluations. Fig. 1 indicates that growth rate recorded in environments differing by about $60 \mathrm{~g}$ /day or more may be regarded as a different trait in genetic evaluations in order to account for GxE. This variation in environmental conditions observed in nucleus herds may be used to select pigs more suited to commercial conditions. For example, traits expressing $\mathrm{GxE}$ may be defined as separate traits for inferior and superior environments observed in nucleus herds to select pigs better suited for the specific needs of commercial herds with inferior or possibly superior environments.

\section{Considering environmental sensitivity in the breeding objective}

The breeding objective should be defined for the environment that is relevant for commercial, crossbred pigs. Selection decisions, however, are made on purebred animals in nucleus farms and environmental conditions may differ between commercial production environments and environments of a nucleus farms due to differences in husbandry, housing and health status. If genotypes differ in their response to variation in environmental conditions, then the genetically superior genes selected for in the nucleus environment may not confer the same gains in commercial conditions with differing environments. Knap

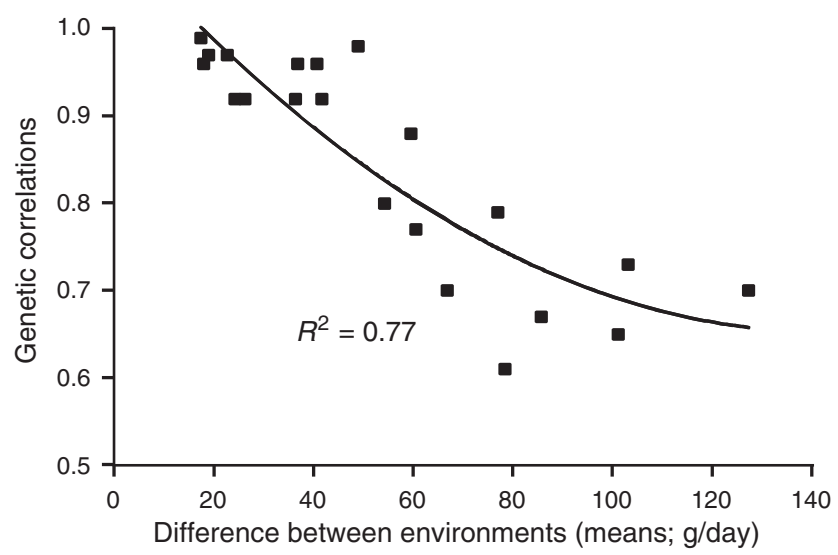

Fig. 1. Genetic correlations for growth rate defined as a separate trait in each environment declined as the difference in mean growth rate between two environments increased ( $\mathrm{Li}$ and Hermesch 2013). 
(2005) presented an approach to derive the economic value for reaction norms of days to reach market weight, assuming that pigs were selected in a superior environment typical for nucleus herds, while production was at an inferior environment representing the average customer farm with lower performance. Economic values for reaction norms were based on the economic value of the underlying performance trait, for example days to market or growth rate. This economic value was multiplied by the difference in the environmental variable of the selection and production environment. It follows that the magnitude of economic value for reaction norms depends on the difference between the selection and production environments and the economic value of the trait of interest. Further, economic values for reaction norms may be negative or positive depending on whether the production environment is below or above the selection environment (Hermesch and Amer 2013). This last point is of interest for Australian pig breeders who often select purebred pigs in very hot environments, which in fact may be inferior to commercial conditions experienced by pigs overseas with more temperate environments and may also be inferior to highly controlled environments prevalent on some commercial farms in Australia.

Hermesch and Amer (2013) compared the relative economic importance of environmental sensitivity of growth (i.e. reaction norms or slope of the reaction norm model) with the economic importance of the level of growth rate (i.e. intercept of the reaction norm model). The comparison demonstrated relatively low economic importance of environmental sensitivity because economic values of reaction norms were only $6 \%$ or $8 \%$ of the economic value for the intercept for growth when compared on the basis of genetic variation of each trait. This comparison assumed that the selection and the average production environment differed by $30 \mathrm{~g} /$ day for growth and $0.9 \mathrm{~mm}$ for backfat. The importance of environmental sensitivity depends on this difference between commercial and selection environment in regard to definition of breeding objectives as well as magnitude of GxE, which can only be estimated reliably if performance records from all environments are available and good genetic links between environments exists.

\section{Disease resilience}

Disease resilience was defined as the ability of a host to maintain a reasonable level of productivity when challenged by infection (Albers et al. 1987). This definition of disease resilience includes productivity and as such affects profitability of livestock production directly. Therefore, it might be more profitable to breed for low production losses due to infection rather than for high resistance to pathogen burden per se (Bisset and Morris 1996). This approach focuses on reducing the effects of infection rather than reducing the infection itself following the earlier work by Clunies-Ross (1932) who made the distinction between 'resistance to infection' and 'resistance to the effects of infection'.

Disease resilience is assessed via the difference in performance of an individual or a family group (e.g. sire family) between environments with different pathogen burden (Bisset and Morris 1996). Often specific measures of pathogen challenge are not known and various performance traits, immune parameters, and veterinary records may be used to estimate infection challenge prevalent for a specific environment (Hermesch 2014). Infection has been defined as the colonisation of a host by a pathogen and disease as the side effects of infection (Bishop and Stear 2003). In this context, infection challenge is the result of the pathogen burden experienced by a group of pigs, which may include multiple pathogens, and the effects of multiple environmental factors that enhance or inhibit the effects of pathogen burden on performance, health and survival of pigs.

Selection for disease resilience uses data available on farms to improve health of animals. Infection challenges experienced by individual animals and epidemiology processes of a disease outbreak are usually not considered. Ignoring different stages of infection of individuals when performance records are collected may bias estimates of disease resilience. This potential bias may be reduced by taking repeated measurements of host performance over a sufficiently long time period to capture the full impact of the infection on performance of individual pigs (Doeschl-Wilson and Lough 2014). In particular, repeated weight and feed intake records available from electronic weight scales and feeders offer opportunities to develop selection strategies for disease resilience because poor growth and reduced feed intake are observed in many diseases where clinical signs are present. Further, even in sub-clinical infections, energy is being directed away from growth towards tissue repair and immune activation (e.g. Collins 2014).

\section{Resistance and tolerance improve disease resilience}

Traits to describe disease resilience used information about pathogen burden in environments (e.g. Bisset and Morris 1996) because information about pathogen levels within a host is usually not available. Therefore, disease resilience defined in this way does not provide information about disease resistance and disease tolerance of the host. Disease resistance is the ability of the host to exert control over the parasite or pathogen life cycle whereas disease tolerance has been defined as the net impact of an infection on performance of a host (e.g. Bishop 2012).

Direct measures of disease resistance relate to the intrinsic ability of animals to fight pathogens and are often based on accurate laboratory analyses of faecal egg count, viraemia or bacterial load to quantify the infection load due to nematodes, viruses or bacteria. It is therefore not surprising that genetic variation has been found for traits describing disease resistance. For example, there is ample evidence for genetic variation in pigs in viral load of the porcine reproductive and respiratory syndrome virus (e.g. Lunney and Chen 2010), and genetic factors including genetic markers affecting susceptibility of pigs to atrophic rhinitis, Escherichia coli infection and Trichinella sprialis were outlined in the review by Crump (1999).

Selection for direct measures of disease resistance reduces within-host pathogen burden, which reduces the overall pathogen burden on farms. The review by Bishop (2012) listed experimental studies in sheep that demonstrated epidemiological benefits arising from populations with improved resistance to nematode infections. This observation provides a strong argument to implement selection strategies for improved disease resistance with beneficial health and welfare consequences for groups of animals, because selection for disease resistance improves environments by reducing pathogen load. 
Disease tolerance may be quantified by changes in performance with increasing pathogen burden. Genetic variation in tolerance implies that genotypes differ in their response to pathogen burden, which again can be quantified with reaction norm models that describe the response of a genotype to varying pathogen burden. However, this requires large datasets with individuals adequately quantified for pathogen burden. Doeschl-Wilson et al. (2012) provided a mathematical framework to quantify tolerance for an individual more precisely based on within-host pathogen burden. Such an approach requires information about (a) repeated measures of host performance and within-host pathogen burden over time for each animal, (b) information about the performance potential of an animal in a pathogen-free environment, and (c) information about other factors influencing performance over time. Although it may be possible to obtain sufficient data to fulfil (b) and (c) from farm data, repeated measures of host performance and pathogen burden for individual animals are currently not routinely available from commercial populations. Therefore, it may not be possible to quantify disease tolerance and to distinguish disease tolerance and disease resistance in practical breeding programs. Group measures of pathogen burden, however, do present an estimate of the overall infection burden prevalent on-farm and may be used to develop new traits for disease resilience, which does not distinguish between disease resistance and disease tolerance.

\section{Immune response and competence}

Pig genotypes have been shown to differ in their response to disease challenges (e.g. Schinckel et al. 1999; Doeschl-Wilson et al. 2009) possibly due to differences in immune parameters, which have been shown to be moderately to highly heritable (e.g. Clapperton et al. 2005, 2008; Henryon et al. 2006; Flori et al. 2011). The wide range of immunity traits was grouped by Flori et al. (2011) into traits describing global immunity, cell-mediated adaptive immunity, humoral-mediated adaptive immunity, innate immunity and other haematological traits. So far, there is no consensus among scientists about the use of specific immunity traits in pig breeding programs. Bishop et al. (2002) pointed out that heritability estimates tend to increase from traits describing general disease category to traits quantifying specific disease resistance and traits measuring specific immune response. This was also observed by Kerr et al. (2005), who found higher heritability estimates for gene-expression traits when extreme observations were included in genetic analyses. These extreme observations may have been due to a disease incidence for specific pigs. However, overall heritability estimates were low for these gene-expression traits that were based on records obtained in a commercial herd. Kerr et al. (2005) mentioned technical and logistical challenges of data collection on-farm and indicated that an acceptable stress challenge that can be applied on farms before collection of blood samples may be required in order to identify genetic differences in immune parameters based on commercial data.

Recently, Hine et al. (2014) reviewed selection strategies for immune competence. The authors concluded that selection for resistance to a specific disease carries the potential risk of increasing the susceptibility to other diseases. This risk is reduced by selection for general immune responsiveness as an alternative or complementary selection strategy to selection for a specific disease. Differential blood counts describe global and innate immunity (Flori et al. 2011), and haptoglobin has been recommended as an important marker of herd health in pigs (Petersen et al. 2004). Maternal effects influence health of progeny and maternal immunoglobulins may be used to quantify the effect of the dam on progeny health (Collins 2014). Overall, these studies indicate that immune parameters offer opportunities for selection to improve health and disease resilience of pigs. However, the consequences of using specific immune parameters in selection decisions have to be monitored.

Unexpected and unfavourable consequences of selection for immune response can be avoided by focusing directly on disease resilience, survival and low incidence of clinical and sub-clinical diseases. In pigs, Henryon et al. (2001) found genetic variation for clinical and sub-clinical disease in pigs that were based on veterinary records from the central test station in Denmark. In addition, genetic variation was found for a simple disease incidence score based on routine veterinary observations on non-specific digestive disorders in a commercial rabbit population (Garreau et al. 2008). These results are noteworthy because simple disease incidence scores were derived from routine veterinary records and genetic variation for disease scores was found in good health and housing conditions. Despite these promising results, selection for improved health remains challenging and information should be collected from as many environments as possible including commercial environments that may have higher incidence of disease than nucleus farms.

\section{Residual feed intake and robustness}

The resource allocation theory developed by Beilharz et al. (1993) defines fitness as a product of separate component traits each requiring environmental resources that are additively allocated to individual processes. Resources available from a specific environment determine the genotype selected in each environment that maximises phenotypic fitness at that environmental level. This matching of genotypes to different environmental resources leads to GxE if environmental resources vary from the resources that were available in the selection environment (Beilharz and Nitter 1998). The equation presented by Beilharz and Nitter (1998) to allocate resources to individual processes is very similar to the linear regression of feed intake on individual components of performance that defines residual feed intake (RFI) as outlined by Rauw (2007), who suggested that 'the similarity between these models implies that calculation of RFI can be used to quantify the amount of 'buffer' resources available to an animal for example physical activity and the ability to cope with unexpected stresses'.

The RFI of pigs can be estimated as the residual of a model for feed intake that includes growth rate, backfat and possibly metabolic bodyweight as covariates (Mrode and Kennedy 1993). In 2000, divergent selection lines for RFI were established in Iowa (USA) and France. The comparison of divergent selection lines at each location showed that selection for lower RFI resulted in more efficient, leaner and slower growing pigs (Dekkers and Gilbert 2010). More recently, pigs from these selections lines have been compared in different environments and have been exposed to various challenges including heat stress and PRRS 
Table 4. Significance $(P$-value; $* * *: P<0.0001)$ of the effects of line, environment and line $\times$ environment interaction, and least square means (LSMEANS) of the line $\times$ environment interaction (Gilbert et al. 2012)

Letters indicate values different at $P<0.05$ within traits. E, environment; FE, France; Europe; FWI, French West Indies; HRFI, high residual feed intake (RFI) selection line; LRFI, low RFI selection line; ADG, average daily gain; ADFI, average daily feed intake; FCR, feed conversion ratio; BF, backfat; wk, weeks

\begin{tabular}{llccccc}
\hline Statistic & Effects & $\begin{array}{c}\text { ADG (g/day) } \\
11-15 \mathrm{wk}\end{array}$ & $\begin{array}{c}\text { ADFI (g/day) } \\
15-23 \mathrm{wk}\end{array}$ & $\begin{array}{c}\text { ADG (g/day) } \\
15-23 \mathrm{wk}\end{array}$ & $\begin{array}{c}\text { FCR (kg:kg) } \\
15-23 \mathrm{wk}\end{array}$ & $\begin{array}{c}\text { BF }(\mathrm{mm}) \\
23 \mathrm{wk}\end{array}$ \\
\hline$P$-value & Line & $* * * *$ & $* * * *$ & 0.33 & $* * * *$ & $* * * *$ \\
& E & $* * * *$ & 0.22 & 0.62 & 0.69 & 0.0008 \\
& Line $\times$ E & 0.04 & 0.71 & 0.02 & 0.008 & $* * * *$ \\
LSMEANS & HRFI $\times$ FE & $797 \mathrm{a}$ & $2290 \mathrm{a}$ & $776 \mathrm{ab}$ & $2.98 \mathrm{a}$ & $18.4 \mathrm{a}$ \\
& LRFI $\times$ FE & $770 \mathrm{a}$ & $2043 \mathrm{~b}$ & $788 \mathrm{ab}$ & $2.61 \mathrm{~b}$ & $15.9 \mathrm{~b}$ \\
& HRFI $\times$ FWI & $583 \mathrm{~b}$ & $2345 \mathrm{a}$ & $806 \mathrm{a}$ & $2.92 \mathrm{a}$ & $15.7 \mathrm{~b}$ \\
& LRFI $\times$ FWI & $510 \mathrm{c}$ & $2080 \mathrm{~b}$ & $773 \mathrm{~b}$ & $2.69 \mathrm{~b}$ & $16.0 \mathrm{~b}$ \\
\hline
\end{tabular}

virus challenge (Gilbert et al. 2012; Campos et al. 2014; Dunkelberger et al. 2015).

Performance of pigs from the French selection lines was compared in the temperate environment prevalent in France, Europe and the tropical environment of the French West Indies (Gilbert et al. 2012; Table 4). In France, growth rate was similar between the two lines during the earlier and later growth phases. In comparison, line differences were larger in the French West Indies for the earlier growth phase from 11 to 15 weeks of age compared with the period from 15 to 23 weeks. The low RFI line grew on average $73 \mathrm{~g} /$ day less in the earlier period than the high RFI line, whereas the difference was $33 \mathrm{~g} /$ day in the later growth period. Overall, these results indicate a higher depressive effect of the tropical environment on growth of low RFI pigs in the early stages of growth that was not fully compensated during the later growth period. However, the line difference was limited for FCR and the low RFI pigs remained more efficient in the tropical environment.

Average daily feed intake of each selection line was similar in each environment in the study by Gilbert et al. (2012). This is unexpected because reduction in feed intake is a main response to heat stress, which has also been observed for these lines in experiments with controlled temperature challenges (Renaudeau et al. 2013; Campos et al. 2014). In the study by Renaudeau et al. (2013), both selection lines had a similar reduction in feed intake resulting from increased temperature whereas the decrease in feed intake due to raised temperature was larger for the high RFI line in the study by Campos et al. (2014). Further, it was found that the low RFI line adapted to the raised temperature more quickly. There were no differences between lines in their response to controlled heat stress in regard to rectal or skin temperature and respiratory or heart rate, confirming results by Renaudeau et al. (2013) that thermal acclimatisation of both selection lines to heat stress was similar. Therefore, selection for feed efficiency based on RFI did not decrease the ability of pigs to withstand heat stress. This finding is relevant for Australia with a hot climate where pigs are exposed to heat stress regularly.

In a subsequent study, environmental sensitivity of these selection lines was investigated by comparing the response in growth to environmental variation observed on farm in France (Gilbert et al. 2014). Effectively, a reaction norm was fitted for each selection line on the estimate of monthly growth environments. Contrary to expectations, it was the high RFI line that had higher environmental sensitivity for growth whereas no line differences were found for backfat. The lower environmental sensitivity in growth of the low RFI line, however, corresponds to findings by Dunkelberger et al. (2015) who compared growth and viral load of the RFI selection lines in Iowa following a challenge with PRRS virus. There was a tendency for pigs from the low RFI line to have a lower viral load $(P=0.09)$, a greater growth rate $(P=0.10)$ and a greater chance of surviving the PRRS virus challenge $(P=0.06)$. Further, the joint analysis of challenged and non-challenged pigs showed a significant interaction between RFI line and challenge status for growth. Growth of the low RFI line was less affected by the PRRS virus challenge than growth of the high RFI line. These results question the hypothesis that high RFI provides a buffer for animals to face stresses and may indicate a more complex relationship between available resources and individual metabolic processes than indicated by the resource allocation theory. Gaining a better understanding of these relationships is important for genetic improvement of productivity and robustness of pigs.

\section{Conclusions}

Pig breeding programs around the world continue to improve both productivity and robustness by extending selection emphasis to a wider range of traits. No trait group can be seen in isolation. Further, genetic improvement itself cannot be viewed in isolation and needs to be accompanied by improvement in management strategies. Selection and management strategies will both lead to continued improvements in performance, health and welfare of pigs. The main conclusions of this review are:

(1) Improving environmental conditions on-farm is the first priority. Genetic analyses disentangle genetic from environmental effects and provide descriptors of environmental conditions in the absence of explicit environmental measures. Estimates of environmental descriptors from genetic analyses could be used to monitor environmental conditions on-farm, which depend on multiple specific environmental factors including the incidence of disease. Furthermore, new technologies in precision agriculture and veterinary practice offer new opportunities to quantify environmental and pathogen challenges better. 
(2) A flexible approach has been presented that facilitates extension of breeding objectives to include further traits that describe productivity and robustness of animals. The level of performance affects the economic importance of some breeding objective traits and breeding objectives should be defined for the commercial environments of the production of pork.

(3) Defining traits for breeding programs to improve health status of pigs remains challenging. The rate of genetic improvement increases as more sources of phenotypic information and genetic information, via marker-assisted selection or genomic selection, are incorporated in genetic evaluations. Information about repeated measures of growth and feed intake, survival of pigs, disease incidence and medication records as well as immune parameters will aid genetic improvement of disease resilience.

(4) Selection for improved health of pigs should incorporate disease resistance traits for infectious diseases such as Escherichia coli infections because selection for improved disease resistance reduces pathogen load on farm and therefore improves environmental conditions for all pigs. The specific infection pathways of each pathogen have to be considered in selection strategies for each specific disease resistance trait.

(5) It is possible to improve productivity and robustness simultaneously. The responses of divergent selection lines for RFI to challenging environments, or controlled heat or PRRS challenges were often similar or even favourable for the more efficient, low RFI line. Further research is required to evaluate why the associations between productivity and robustness traits have been variable between studies. This requires better understanding of the metabolic differences between more or less productive pigs to comprehend the interactions of the genetic potential of pigs for productivity and robustness and the prevalence of specific environmental conditions.

\section{Acknowledgements}

Supported in part by Australian Pork CRC. The manuscript was prepared while Susanne Hermesch stayed at INRA in Castanet-Tolosan, France. Support from INRA and INP Toulouse for a 'Professeur Visiteur 2015' award is gratefully acknowledged. Further, we thank Kim Bunter and Cherie Collins for constructive comments.

\section{References}

Akanno EC, Schenkel FS, Quinton VM, Friendship RM, Robinson JAB (2013) Meta-analysis of genetic parameter estimates for reproduction, growth and carcass traits of pigs in the tropics. Livestock Science 152, 101-113. doi:10.1016/j.livsci.2012.07.021

Albers GAA, Gray GD, Piper LR, Barker JSF, Lejambre LF, Barger IA (1987) The genetics of resistance and resilience to Haemonchus-contortus infection in young Merino sheep. International Journal for Parasitology 17, 1355-1363. doi:10.1016/0020-7519(87)90103-2

Amer PR, Ludemann CI, Hermesch S (2014) Economic weights for maternal traits of sows, including sow longevity. Journal of Animal Science $\mathbf{9 2}$, 5345-5357. doi:10.2527/jas.2014-7943

Barwick SA, Henzell AL (2005) Development successes and issues for the future in deriving and applying selection indexes for beef breeding. Australian Journal of Experimental Agriculture 45, 923-933. doi:10.1071/ EA05068
Barwick SA, Swan AA, Hermesch S, Graser HU (2011) Experience in breeding objectives for beef cattle, sheep and pigs, new developments and future needs. In 'Proceedings of the 19th conference of the Association for the Advancement of Animal Breeding and Genetics'. (Ed. P Vercoe) pp. 23-30. (Association for the Advancement of Animal Breeding and Genetics: Perth)

Beilharz RG, Nitter G (1998) The missing E: the role of the environment in evolution and animal breeding. Journal of Animal Breeding and Genetics-. Zeitschrift für Tierzüchtung und Züchtungsbiologie 115, 439-453.

Beilharz RG, Luxford BG, Wilkinson JL (1993) Quantitative genetics and evoluation - is our understanding of genetics sufficient to explain evolution. Journal of Animal Breeding and Genetics-Zeitschrift für Tierzüchtung und Züchtungsbiologie 110, 161-170. doi:10.1111/ j.1439-0388.1993.tb00728.x

Bishop SC (2012) A consideration of resistance and tolerance for ruminant nematode infections. Frontiers in Genetics 3, 168. doi:10.3389/fgene. 2012.00168

Bishop SC, Stear MJ (2003) Modeling of host genetics and resistance to infectious diseases: understanding and controlling nematode infections. Veterinary Parasitology 115, 147-166. doi:10.1016/S0304-4017(03) 00204-8

Bishop SC, Chesnais J, Stear MJ (2002) Breeding for disease resistance: issues and opportunities. In 'Proceedings of the 7th World Congress on Genetics Applied to Livestock Production.' (Ed. INRA) (Institut National de la Recherche Agronomique (INRA): Montpellier)

Bisset SA, Morris CA (1996) Feasibility and implications of breeding sheep for resilience to nematode challenge. International Journal for Parasitology 26, 857-868. doi:10.1016/S0020-7519(96)80056-7

Bunter KL (2009) Managing consequences of increasing litter size: a genetics perspective. In 'Manipulating pig production XII'. (Ed. RJ van Barneveld) pp. 149-156. (Australasian Pig Science Association: Melbourne)

Bunter KL, Hermesch S, Luxford BG, Graser HU, Crump RE (2005) Insulinlike growth factor-I measured in juvenile pigs is genetically correlated with economically important performance traits. Australian Journal of Experimental Agriculture 45, 783-792. doi:10.1071/EA05048

Bunter KL, Lewis CRG, Hermesch S, Smits R, Luxford BG (2010) Maternal capacity, feed intake and body development in sows. In 'Proceedings of the 9th World Congress on Genetics Applied to Livestock Production'. (Ed. Gesellschaft für Tierzuchtwissenschaften e.V.) (Gesellschaft für Tierzuchtwissenschaften e.V.: Leipzig, Germany)

Cameron ND, Crump RE (2001) Economic values for the Australian pig industry. In 'Manipulating Pig Production VIII. Adelaide', 25-28 November 2001. (Ed. PD Cranwell) p. 146. (Australasian Pig Science Association: Melbourne)

Campos P, Noblet J, Jaguelin-Peyraud Y, Gilbert H, Mormede P, Donzele R, Donzele JL, Renaudeau D (2014) Thermoregulatory responses during thermal acclimation in pigs divergently selected for residual feed intake. International Journal of Biometeorology 58, 1545-1557.

Casey DS, Stern HS, Dekkers JCM (2005) Identification of errors and factors associated with errors in data from electronic swine feeders. Journal of Animal Science 83, 969-982.

Clapperton M, Bishop SC, Cameron ND, Glass EJ (2005) Associations of acute phase protein levels with growth performance and with selection for growth performance in Large White pigs. Animal Science 81, 213-220. doi:10.1079/ASC50180213

Clapperton M, Glass EJ, Bishop SC (2008) Pig peripheral blood mononuclear leucocyte subsets are heritable and genetically correlated with performance. Animal 2, 1575-1584. doi:10.1017/S1751731108002929

Clunies-Ross I (1932) Observations on the resistance of sheep to infestation by the stomach worm Haemonchus contortus. Journal. Council for Scientific and Industrial Research (Australia) 5, 73-80.

Collins A (2014) On-farm measures to monitor the health and immune status of pigs. In 'Breeding focus 2014 - improving resilience'. (Eds S 
Hermesch, S Dominik) pp. 31-47. (Animal Genetics and Breeding Unit: Armidale, NSW)

Crump RE (1999) Breeding for increased disease resistance. In 'Manipulating pig production VII'. (Ed. PD Cranwell) pp. 82-87. (Australasian Pig Science Association: Melbourne)

Dekkers JCM, Gilbert H (2010) 'Genetic and biological aspect of residual feed intake in pigs, In 'Proceedings of the 9th world congress on genetics applied to livestock production'. (Ed. Gesellschaft für Tierzuchtwissenschaften e.V.) (Gesellschaft für Tierzuchtwissenschaften e.V.: Leipzig, Germany)

Doeschl-Wilson AB, Lough G (2014) Inferring genetic resilience of animals to infectious pathogens - opportunities and pitfalls. In 'Breeding focus 2014 - improving resilience'. (Eds S Hermesch, S Dominik) pp. 19-30. (Animal Genetics and Breeding Unit: Armidale, NSW)

Doeschl-Wilson AB, Kyriazakis I, Vincent A, Rothschild MF, Thacker E, Galina-Pantoja L (2009) Clinical and pathological responses of pigs from two genetically diverse commercial lines to porcine reproductive and respiratory syndrome virus infection. Journal of Animal Science 87, 1638-1647. doi:10.2527/jas.2008-1447

Doeschl-Wilson AB, Bishop SC, Kyriazakis I, Villanueva B (2012) Novel methods for quantifying individual host response to infectious pathogens for genetic analyses. Frontiers in Genetics 3, 266. doi:10.3389/fgene. 2012.00266

Dufrasne M, Misztal I, Tsuruta S, Gengler N, Gray KA (2014) Genetic analysis of pig survival up to commercial weight in a crossbred population. Livestock Science 167, 19-24. doi:10.1016/j.livsci.2014.05.001

Dunkelberger JR, Boddicker NJ, Serao NVL, Young JM, Rowland RRR, Dekkers JCM (2015) Response of pigs divergently selected for residual feed intake to experimental infection with the PRRS virus. Livestock Science 177, 132-141. doi:10.1016/j.livsci.2015.04.014

Eissen JJ, Kanis E, Merks JWM (1998) Algorithms for identifying errors in individual feed intake data of growing pigs in group-housing. Applied Engineering in Agriculture 14, 667-673. doi:10.13031/2013.19421

Falconer DS, Mackay TFC (1996) 'Introduction to quantitative genetics.' (Longman Group: Essex, UK)

Flori L, Gao Y, Laloe D, Lemonnier G, Leplat JJ, Teillaud A, Cossalter AM, Laffitte J, Pinton P, de Vaureix C, Bouffaud M, Mercat MJ, Lefevre F, Oswald IP, Bidanel JP, Rogel-Gaillard C (2011) Immunity traits in pigs: substantial genetic variation and limited covariation. PLoS One 6, e22717. doi:10.1371/journal.pone. 0022717

Garreau H, Eady SJ, Hurtaud J, Legarra A (2008) Genetic parameters of production traits and resistance to digestive disorders in a commercial rabbit population. In 'Proceedings of the 9th world rabbit congress', Verona, Italy, 10-13 June 2008. (Eds G Xiccato, A Trocino, SD Lukefahr) pp. 103-107. (Fondazione Iniziative Zooprofilattiche E Zootecniche: Brescia)

Gilbert H, Billon Y, Fleury J, Noblet J, Gourdine JL, Renaudeau D (2012) Are responses to selection in lines divergently selected for residual feed intake in growing pigs affected by $\mathrm{GxE}$ interactions when bred in a tropical environment? In 'Proceedings of the AnGR-NordicNET workshop, genotype-by-environment interactions and adaptation of farm animals on phenotypic and molecular levels'. Tuusula, Finnland, 7-8 November 2012. (Eds A Præbel, T Nygård Kristensen) pp. 26-27. (NordGen - the Nordic Genetic Resource Center: Ås)

Gilbert H, David I, Billon Y, Hermesch S (2014) Does selection for RFI affect the sensitivity to environmental variation in pigs? In '10th world congress of genetics applied to livestock production. Vancouver, Canada'. Paper 123. (American Society of Animal Science: Vancouver)

Guy SZY, Thomson PC, Hermesch S (2012) Selection of pigs for improved coping with health and environmental challenges: breeding for resistance or tolerance? Frontiers in Genetics 3, 281. doi:10.3389/fgene.2012.00281

Haskell MJ, Brotherstone S, Lawrence AB, White IMS (2007) Characterization of the dairy farm environment in great Britain and the effect of the farm environment on cow life span. Journal of Dairy Science 90, 5316-5323. doi:10.3168/jds.2006-865

Henryon M, Berg P, Jensen J, Andersen S (2001) Genetic variation for resistance to clinical and subclinical disease exists in growing pigs. Animal Science 73, 375-387.

Henryon M, Heegaard PMH, Nielsen J, Berg P, Juul-Madsen HR (2006) Immunological traits have the potential to improve selection of pigs for resistance to clinical and subclinical disease. Animal Science 82, 597-606. doi:10.1079/ASC200671

Hermesch S (2001) Avenues for genetic improvement of litter size and litter mortality. In '2001 AGBU pig genetics workshop notes. Armidale'. pp. 36-43. (Animal Genetics and Breeding Unit: Armidale, NSW)

Hermesch S (2004) Genetic improvement of lean meat growth and feed efficiency in pigs. Australian Journal of Experimental Agriculture 44, 383-391. doi:10.1071/EA04017

Hermesch S (2006) From genetic to phenotypic trends. In '2006 AGBU pig genetics workshop notes. Armidale'. pp. 59-65. (Animal Genetics and Breeding Unit: Armidale, NSW)

Hermesch S (2014) Breeding disease resilient pigs. In 'Breeding focus 2014 improving resilience'. (Eds S Hermesch, S Dominik) pp. 5-17. (Animal Genetics and Breeding Unit: Armidale, NSW)

Hermesch S, Amer PR (2013) Deriving economic values for reaction norms of growth in pigs. In 'Proceedings of the 20th conference of the Association for the Advancement of Animal Breeding and Genetics'. (Ed. NL Villalobos) pp. 475-478. (Association for the Advancement of Animal Breeding and Genetics: Napier)

Hermesch S, Jones RM (2010) Strategies to improve market value of pig carcases. In '2010 AGBU pig genetics workshop notes'. (Eds S Hermesch, K Dobos) pp. 39-46. (Animal Genetics and Breeding Unit: Armidale, NSW)

Hermesch S, Luxford BG, Graser HU (2001) Estimation of variance components for individual piglet weights at birth and 14 days of age. In 'Proceedings of the 14th conference of the Association for the Advancement of Animal Breeding and Genetics'. pp. 207-210. (Association for the Advancement of Animal Breeding and Genetics: Queenstown)

Hermesch S, Jones RM, Bunter KL, Gilbert H (2010) Consequences of selection for lean growth and prolificacy on sow attributes. In 'Proceedings of the 9th World Congress of Genetics Applied to Livestock Production.' (Ed. Gesellschaft für Tierzuchtwissenschaften e.V.) (Gesellschaft für Tierzuchtwissenschaften e.V.: Leipzig, Germany)

Hermesch S, Ludemann CI, Am PR (2014a) Economic weights for performance and survival traits of growing pigs. Journal of Animal Science 92, 5358-5366. doi:10.2527/jas.2014-7944

Hermesch S, Parke CR, Bauer MM, Gilbert H (2014b) Maternal genetic effects for lifetime growth should be considered more in pig breeding. In 'Proceedings of the 10th world congress of genetics applied to livestock production', Vancouver, Canada. Paper 367. (American Society of Animal Science: Vancouver)

Hermesch S, Sokolinski R, Johnston R, Newman S (2015) Economic implications of environmental variation observed in a pig nucleus farm in Australia. In 'Manipulating pig production XV'. (Eds JR Pluske, JM Pluske) p. 1466. (Australasian Pig Science Association: Melbourne)

Herrero-Medrano JM, Mathur PK, ten Napel J, Rashidi H, Alexandri P, Knol EF, Mulder HA (2015) Estimation of genetic parameters and breeding values across challenged environments to select for robust pigs. Journal of Animal Science 93, 1494-1502.

Hine BC, Mallard BA, Ingham AB, Colditz IG (2014) Immune competence in livestock. In 'Breeding focus 2014 - improving resilience'. (Eds S Hermesch, S Dominik.) pp. 49-64. (Animal Genetics and Breeding Unit, University of New England: Armidale, NSW)

Huquet B, Leclerc H, Ducrocq V (2012) Characterization of French dairy farm environments from herd-test-day profiles. Journal of Dairy Science $\mathbf{9 5}$, 4085-4098. doi:10.3168/jds.2011-5001 
Hyun Y, Ellis M, Riskowski G, Johnson RW (1998) Growth performance of pigs subjected to multiple concurrent environmental stressors. Journal of Animal Science 76, 721-727.

Johnson ZB, Chewning JJ, Nugent RA III (2002) Maternal effects on traits measured during postweaning performance test of swine from four breeds. Journal of Animal Science 80, 1470-1477.

Kanis E, De Greef KH, Hiemstra A, van Arendonk JAM (2005) Breeding for societally important traits in pigs. Journal of Animal Science 83, 948-957.

Kerr CA, Bunter KL, Seymour R, Shen B, Reverter A (2005) The heritability of the expression of two stress-regulated gene fragments in pigs. Journal of Animal Science 83, 1753-1765.

Knap PW (2005) Breeding robust pigs. Australian Journal of Experimental Agriculture 45, 763-773. doi:10.1071/EA05041

Knap PW, Rauw WM (2009) Selection for high production in pigs. In 'Resource allocation theory applied to farm animal production'. (Ed. WM Rauw) pp. 210-229. (Centre for Agriculture and Biosciences International: Wallingford, UK)

Knap PW, Su G (2008) Genotype by environment interaction for litter size in pigs as quantified by reaction norms analysis. Animal 2, 1742-1747. doi: $10.1017 / \mathrm{s} 1751731108003145$

Knap PW, Wang L (2012) Pig breeding for improved efficiency. In 'Feed efficiency in swine'. (Ed. JF Patience) pp. 167-182. (Wageningen Academic Publishers: Wageningen)

Lewis CRG, Torremorell M, Galina-Pantoja L, Bishop SC (2009) Genetic parameters for performance traits in commercial sows estimated before and after an outbreak of porcine reproductive and respiratory syndrome. Journal of Animal Science 87, 876-884. doi:10.2527/jas.2008-0892

Li L, Hermesch S (2012) Genotypes differ in their response to variation in environments experienced by pigs on farm. In '2012 AGBU pig genetics workshop notes. Armidale'. (Eds S Hermesch, K Dobos) pp. 53-60. (Animal Genetics and Breeding Unit: Armidale, NSW)

Li L, Hermesch S (2013) Genotype by environment interactions for average daily gain using multiple-trait analyses in Australian pigs. Proceedings of the Association for the Advancement of Animal Breeding and Genetics 20, 323-326.

Li L, Hermesch S (2015) Environmental variation and breed sensitivity for growth rate and backfat depth in pigs. Animal Production Science. doi:10.1071/AN14066

Lunney JK, Chen HB (2010) Genetic control of host resistance to porcine reproductive and respiratory syndrome virus (PRRSV) infection. Virus Research 154, 161-169. doi:10.1016/j.virusres.2010.08.004

Lutaaya E, Misztal I, Mabry JW, Short T, Timm HH, Holzbauer R (2001) Genetic parameter estimates from joint evaluation of purebreds and crossbreds in swine using the crossbred model. Journal of Animal Science 79, 3002-3007.

McSweeny JM, Hermesch S, Crump RE, Luxford BG (2001) Factors causing a reduction in individual feed intake data of group-housed pigs recorded with electronic feeders. Proceedings of the Association for the Advancement of Animal Breeding and Genetics 14, 369-372.
Merks JWM (1989) Genotype x Environment interactions in pig breeding programmes. VI. Genetic relations between performances in central test, on-farm test and commercial fattening. Livestock Production Science 22, 325-339. doi:10.1016/0301-6226(89)90064-X

Merks JWM, Mathur PK, Knol EF (2012) New phenotypes for new breeding goals in pigs. Animal 6, 535-543. doi:10.1017/S1751731111002266

Mrode RA, Kennedy BW (1993) Genetic variation in measures of food efficiency in pigs and their genetic relationships with growth rate and backfat. Animal Production 56, 225-232. doi:10.1017/S00033561000 21309

Nicholas FW (1997) A review - pig genetics into the 21st century. In 'Manipulating pig production VI'. (Ed. PD Cranwell) pp. 149-164. (Australasian Pig Science Association: Melbourne)

Petersen HH, Nielsen JP, Heegaard PMH (2004) Application of acute phase protein measurements in veterinary clinical chemistry. Veterinary Research 35, 163-187. doi:10.1051/vetres:2004002

Phocas F, Bobe J, Bodin L, Charley B, Dourmad JY, Friggens NC, Hocquette JF, Bail PY, Le Bihan-Duval E, Mormede P, Quere P, Schelcher F (2014) Des animaux plus robustes: un enjeu majeur pour le développement durable des productions animales nécessitant l'essor du phénotypage fin et à haut debit. Productions Animales 27, 181-194.

Prunier A, Heinonen M, Quesnel H (2010) High physiological demands in intensively raised pigs: impact on health and welfare. Animal 4, 886-898. doi:10.1017/S175173111000008X

Rashidi H, Mulder HA, Mathur P, van Arendonk JAM, Knol EF (2014) Variation among sows in response to porcine reproductive and respiratory syndrome. Journal of Animal Science 92, 95-105. doi:10.2527/jas.20136889

Rauw WM (2007) Physiological consequences of selection for increased performance. In 'Genetic improvement: making it happen. In 'Proceedings of the 17th conference of the Association for the Advancement of Animal Breeding and Genetics'. (Ed. K Donoghue, B Pattie, B Restall, B Kinghorn) pp. 204-247. (Association for the Advancement of Animal Breeding and Genetics: Armidale, NSW)

Renaudeau D, Frances G, Dubois S, Gilbert H, Noblet J (2013) Effect of thermal heat stress on energy utilization in two lines of pigs divergently selected for residual feed intake. Journal of Animal Science 91, 1162-1175. doi:10.2527/jas.2012-5689

Schinckel AP, Richert BT, Frank JW, Kendall DC (1999) Genetic by environmental interactions for pig growth. Purdue University 1999 Swine Day Report. http://www.ansc.purdue.edu/swine/swineday/ sday99/13.pdf [Verified 14 September 2015]

Solanes FX, Grandinson K, Rydhmer L, Stern S, Andersson K, Lundeheim N (2004a) Direct and maternal influences on the early growth, fattening performance, and carcass traits of pigs. Livestock Production Science 88, 199-212. doi:10.1016/j.livprodsci.2003.12.002

Solanes FX, Kihlberg M, Andersson K, Lundeheim N (2004b) Maternal effects on daily weight gain and ultrasonically recorded backfat in Swedish Landrace, Swedish Yorkshire, and Swedish Hampshire purebred pigs. Acta Agriculturae Scandinavica Section A-Animal Science 54, 67-74. doi:10.1080/09064700410032004 